\title{
Dynamic optimization of methanol synthesis section in the dual type configuration to increase methanol production
}

\author{
Samane Masoudi, Mohammad Farsi*, and Mohammad Reza Rahimpour \\ Department of Chemical Engineering, School of Chemical and Petroleum Engineering, Shiraz University, Shiraz 71345, Iran
}

Received: 9 March 2019 / Accepted: 13 November 2019

\begin{abstract}
The main object of this research is dynamic modeling and optimization of the methanol synthesis section in the dual type configuration considering catalyst deactivation to improve methanol production capacity. In the methanol unit, deactivation of $\mathrm{CuO} / \mathrm{ZnO} / \mathrm{Al}_{2} \mathrm{O}_{3}$ catalyst by sintering and low equilibrium conversion of reactions limit the production capacity, and changing operating temperature is a practical solution to overcome the production decay. In the first step, the considered process is modeled based on the mass and energy balance equations at dynamic condition. To prove the accuracy of developed model, the simulation results are compared with the plant data at the same operating conditions. In the second step, a dynamic optimization problem is formulated, and the optimal trajectories of manipulated variables are determined considering methanol production rate as the objective function. Finally, the performance of optimized process is compared with the conventional system at the same design conditions. The results show that operating at the optimal conditions increases methanol production capacity about $6.45 \%$.
\end{abstract}

\section{Nomenclature}

$a$

$A_{C}$

Ct

$C_{p}$

$D$

$E_{d}$

$F_{t}$

$f_{i}$

$K_{i}$

$K_{p}$

$k_{1}$

$k_{2}$

$k_{3}$

$K_{d}$

$P$

$r_{1}$
Activity of catalyst (-)

Cross section area of each tube $\left(\mathrm{m}^{2}\right)$

Total concentration $\left(\mathrm{mol} \mathrm{m}^{-3}\right)$

Specific heat of the gas at constant pressure $\left(\mathrm{J} \mathrm{mol}^{-1} \mathrm{~K}^{-1}\right)$

Diameter (m)

Activation energy used in the deactivation model $\left(\mathrm{J} \mathrm{mol}^{-1}\right)$

Total molar flow rate $\left(\mathrm{mol} \mathrm{s}^{-1}\right)$

Partial fugacity of component $i$ (bar)

Adsorption equilibrium constant for component $i\left(\operatorname{bar}^{-1}\right)$

$K_{p} \quad$ Equilibrium constant based on partial pressure for component $i(-)$

Reaction rate constant for the first rate equation ( $m o l ~ \mathrm{~kg}^{-1} \mathrm{~s}^{-1} \mathrm{bar}^{-1 / 2}$ )

Reaction rate constant for the second rate equation ( $m o l ~ \mathrm{~kg}^{-1} \mathrm{~s}^{-1} \operatorname{bar}^{-1 / 2}$ )

3 Reaction rate constant for the third rate equation ( $\mathrm{mol} \mathrm{kg} \mathrm{s}^{-1} \mathrm{bar}^{-1 / 2}$ )

$$
\text { Deactivation constant }\left(\mathrm{h}^{-1}\right)
$$

Total pressure (bar)

Rate of reaction for hydrogenation of $\mathrm{CO}$ $\left(\mathrm{mol} \mathrm{kg} \mathrm{s}^{-1} \mathrm{~s}^{-1}\right)$

\footnotetext{
* Corresponding author: farsi@shirazu.ac.ir
}

$r_{2} \quad$ Rate of reaction for hydrogenation of $\mathrm{CO}_{2}$ $\left(\mathrm{mol} \mathrm{kg} \mathrm{ks}^{-1}\right)$

$r_{3} \quad$ Reversed water-gas shift reaction $\left(\mathrm{mol} \mathrm{kg}^{-1} \mathrm{~s}^{-1}\right)$

$T \quad$ Bulk gas phase temperature $(\mathrm{K})$

$T_{c} \quad$ Temperature of cooling water in first reactor $(\mathrm{K})$

$T_{\text {tube }} \quad$ Temperature of cooling gas in second reactor $(\mathrm{K})$

$T_{R} \quad$ Reference temperature used in the deactivation model (K)

$t \quad$ Time $(\mathrm{s})$

$u \quad$ Superficial velocity of fluid phase $\left(\mathrm{m} \mathrm{s}^{-1}\right)$

$U \quad$ Overall heat transfer coefficient $\left(\mathrm{W} \mathrm{m}{ }^{-2} \mathrm{~K}^{-1}\right)$

$y_{i} \quad$ Mole fraction of component $i(-)$

$z \quad$ Axial reactor coordinate $(\mathrm{m})$

\section{Greek letters}

$\Delta H_{i} \quad$ Heat of reaction $\left(\mathrm{kJ} \mathrm{mol}^{-1}\right)$

$\rho_{B} \quad$ Density of catalytic bed $\left(\mathrm{kg} \mathrm{m}^{-3}\right)$

$\varepsilon_{B} \quad$ Void fraction of catalytic bed (-)

$\mu \quad$ Gas viscosity $\left(\right.$ pa s $\left.^{-1}\right)$

$\eta \quad$ Catalyst effectiveness factor $(-)$

$\sigma_{i} \quad$ Collision diameter of species $i(\AA)$

\section{Subscripts \\ $c \quad$ Catalyst \\ $g \quad$ In gas phase}




$\begin{array}{ll}i & \text { Chemical species } \\ p & \text { Tube side } \\ s & \text { Shell side }\end{array}$

\section{Abbreviations}

DC Dual Configuration

ODC Optimized Dual Configuration

OMDC Optimized Modified Dual Configuration

\section{Introduction}

Nowadays methanol as a building block to produce chemicals, solvents and fuels plays an important role in the petrochemical and chemical industries [1, 2]. It is the main feedstock to produce acetic acid, formaldehyde, dimethyl ether, melamine resin, ethylene and propylene. Currently, methanol has been proposed as a clean alternative green energy source that could be used in the internal combustion and other engines [3]. Although wood distillation is the oldest route to produce methanol, the catalytic syngas conversion is the main commercial technology that carried out in the presence of $\mathrm{CuO} / \mathrm{ZnO} / \mathrm{Al}_{2} \mathrm{O}_{3}$ catalyst [4]. The ICI, Lurgi, Mitsubishi, Haldor Topsoe, Linde and Casale companies are common licensors that developed different technologies to convert syngas to methanol [5]. Mitsubishi Company used the conventional adiabatic reactors in the methanol plants. In the ICI process, the methanol is synthesized in the adiabatic reactors supported by quench points to inject a part of feed stream to the reactor for direct cooling. Since the methanol synthesis reactions are exothermic and reversible, decreasing reaction temperature by quench stream shifts reactions toward the methanol synthesis side. Lurgi and Linde utilized the isothermal reactor for methanol synthesis. The isothermal reactor is a shell and tube exchanger that the tube side is packed by catalyst and the heat of reaction is removed from reaction zone by circulating boiling water in the shell. The proposed plate isothermal reactor by Casale is a radial flow plate heat exchanger that the cooling medium flows in the plates and feed stream flows in the radial direction [6-8]. Generally, fixed and fluidized bed isothermal reactors are more attractive compared to other types at the same catalyst loading due to favorable temperature profile along the reactor.

Low equilibrium conversion of syngas to methanol and deactivation of the catalyst by thermal and chemical sintering and sulfur poisoning are the main challenges in the methanol plant, which limit production capacity. In this regard, many researches have focused on the kinetic modeling, process optimization and modification to improve production rate in the industrial methanol plants. Setinc and Levec presented a kinetic model to describe the rate of methanol synthesis over $\mathrm{CuO} / \mathrm{ZnO} / \mathrm{Al}_{2} \mathrm{O}_{3}$ catalyst based on the Langmuir-Hinshelwood model. The results showed that the Langmuir-Hinshelwood kinetic model is a suitable tool to describe rate of reactions [9]. Although the $\mathrm{CuO} /$ $\mathrm{ZnO} / \mathrm{Al}_{2} \mathrm{O}_{3}$ presents a rather long lifetime and activity compared to other catalysts, it is very sensitive to sulfur poisoning, and the sulfur content in the feed stream needs to be reduced to less than $0.5 \mathrm{ppm}$ [10]. In addition, it can be deactivated thermally, especially at above $300{ }^{\circ} \mathrm{C}$ because of the growth of the $\mathrm{Cu}$ crystallites and the resulting loss of catalytically active area. Liu et al. presented a good review on developed catalysts for methanol synthesis via hydrogenation of $\mathrm{CO}$ and $\mathrm{CO}_{2}$ [11]. Rezaie et al. compared the precision of heterogeneous and homogeneous models to predict performance of a single-stage methanol synthesis reactor [12]. In the heterogeneous modeling, the mass and energy transfer resistances in the $\mathrm{CuO} / \mathrm{ZnO} /$ $\mathrm{Al}_{2} \mathrm{O}_{3}$ catalyst and gas phase were considered in the model. The simulation results showed that both homogeneous and heterogeneous models present a similar accuracy to predict reactor performance. Jahanmiri and Eslamloueyan modeled a single-stage methanol reactor and calculated the optimal temperature profile along the reactor at steady state condition. The results showed that applying the optimal temperature on the reactor could increase methanol production [13]. Kordabadi and Jahanmiri modified the methanol synthesis reactor to enhance the equilibrium conversion. They supported a single-stage reactor by two series cooling shells and calculated the optimum temperature of each shell to achieve maximum methanol production. The simulation results showed that the modification of conventional reactor based on the proposed idea increased methanol production rate over $\mathrm{CuO} / \mathrm{ZnO} / \mathrm{Al}_{2} \mathrm{O}_{3}$ catalyst about $2.9 \%$ [14]. Fuad et al. modeled a single-stage methanol synthesis reactor considering catalyst deactivation and formulated a realtime optimization strategy to improve process performance. The results showed that changing coolant temperature is a practical solution to overcome the catalyst decay and prevent the decline in methanol production [15]. Rahimpour proposed the dual bed concept based on the $\mathrm{CuO} / \mathrm{ZnO} /$ $\mathrm{Al}_{2} \mathrm{O}_{3}$ catalyst as a suitable configuration to overcome thermodynamic limitations in the methanol plants. In the proposed configuration the first reactor was cooled by cooling water, while the second one was cooled by the feed stream. The proposed configuration was heterogeneously modeled at dynamic condition. The results showed that applying dual bed configuration in the methanol plant increased catalyst lifetime and resulted in the higher syngas conversion [16]. Askari et al. calculated the optimal operating conditions of the dual-bed configuration considering cooling temperature in the water cooled reactor and feed temperature as the decision variables. The results showed that applying the optimal condition on the system improved the production capacity about 5.8\% [17].

Since the methanol synthesis reactions are exothermic and reversible, integration of reaction and separation is an effective method to improve methanol production. Farsi and Jahanmiri investigated the dynamic operability of dual membrane reactor considering deactivation of $\mathrm{CuO} / \mathrm{ZnO} /$ $\mathrm{Al}_{2} \mathrm{O}_{3}$ catalyst to produce methanol [18]. In this configuration, a conventional reactor has been supported by a $\mathrm{Pd} / \mathrm{Ag}$ membrane tube for hydrogen permeation and alumina-silica composite membrane tube to remove water vapor from the reaction zone. The results showed that main advantages of the dual-membrane reactor were higher catalyst activity 
and lifetime, higher $\mathrm{CO}_{2}$ conversion and methanol production. Rahimpour and Elekaei modeled a bubbling fluidizedbed membrane dual-type methanol reactor considering long-term deactivation of $\mathrm{CuO} / \mathrm{ZnO} / \mathrm{Al}_{2} \mathrm{O}_{3}$ catalyst. In the proposed process, the feed stream is preheated in the tubes of the gas cooled reactor and hydrogen is penetrated from feed into the reaction side through the membrane [19]. The outlet feed from gas cooled reactor is fed to tubes of the water cooled reactor. The outlet product from water cooled reactor is fed into the shell side of gas cooled reactor and the reactions are completed in the fluidized-bed side. This configuration solves some observed drawbacks of conventional dual-type reactor such as pressure drop, internal mass transfer limitations, radial gradient of concentration and temperature in gas cooled reactor. Rahimpour et al. proposed a cascade fluidized-bed hydrogen permselective membrane reactor to overcome thermodynamic limitations in methanol synthesis process [8]. In the fluidized-bed water cooled reactor, the synthesis gas is partly converted to methanol over the $\mathrm{CuO} / \mathrm{ZnO} / \mathrm{Al}_{2} \mathrm{O}_{3}$ catalyst. In the second bed which is a membrane assisted fluidized-bed reactor, the reaction heat is used to preheat the feed stream in the first bed. The two-phase theory in bubbling regime was used to model and simulate the proposed reactors. The results showed that fluidizing catalyst bed in the water cooled reactor caused a favorable temperature profile in the reactor and represented $3.94 \%$ and $9.53 \%$ enhancement in the methanol yield compared to fluidized-bed membrane dualtype and industrial dual-type reactors. The dynamic simulation of cascade fluidized-bed hydrogen permselective membrane reactor shows that favorable temperature profile in the reactors could decrease catalyst decay [20]. Dehghani et al. proposed a sorption-enhanced configuration with in situ water adsorption for methanol synthesis to decrease sintering of $\mathrm{CuO} / \mathrm{ZnO} / \mathrm{Al}_{2} \mathrm{O}_{3}$ catalyst by steam and improving methanol production [21]. In the proposed configuration, the zeolite $4 \mathrm{~A}$ flows in the methanol synthesis reactor and produced steam is selectively absorbed by solid particles. A theoretical investigation was performed to evaluate the optimal operating condition and maximize the methanol production in the proposed configuration.

Typically, increasing production capacity and decreasing direct and indirect $\mathrm{CO}_{2}$ emissions are attractive challenges in the chemical plants. In this regard, the main object of this research is dynamic optimization of the dual-type methanol synthesis loop in the presence of catalyst deactivation to improve production capacity and $\mathrm{CO}_{2}$ conversion. In the first step, the considered process is modeled based on the mass and energy balance equations at dynamic condition. In the second step, a dynamic optimization problem is formulated and the optimal trajectories of the feed temperature and cooling temperature are determined. In the third step, the process is supported by two heat exchangers and the optimal trajectories of the available inputs are determined during the process run time. Generally, supporting the dual type configuration by two heat exchangers increases the number of manipulated variables and results in the suitable heat management in the system.

\section{Methods}

The main object of this research is dynamic optimization of syngas conversion section in the methanol plant to increase methanol production and $\mathrm{CO}_{2}$ conversion. In this part, the process description, considered kinetic and process models, formulated optimization algorithm and considered method to solve the optimization problem and obtained equations are presented.

\subsection{Process description}

Figure 1 shows the process flow diagram of syngas conversion section in the considered methanol unit [22]. The methanol unit consists of three main steps including syngas production from natural gas, methanol synthesis from syngas and downstream purification sections. The methanol synthesis section consists of two water cooled reactors aligned in parallel, and gas cooled reactor in series with water cooled reactors. The $\mathrm{CuO} / \mathrm{ZnO} / \mathrm{Al}_{2} \mathrm{O}_{3}$ catalyst is packed in the shell side of gas cooled, and in the tubes of water cooled reactors. Typically, the produced syngas in the steam methane reforming unit feeds to the tube side of gas cooled reactor. The outlet preheated stream from tubes of gas cooled reactor directly feeds to the tube side of water cooled reactor and syngas is partially converted to methanol. The heat produced in the tubes is transferred to saturated water in the shell side. The outlet stream from shell side of water cooled reactor feeds to the shell side of the gas cooled reactor. Since the shell side of gas cooled reactor is packed by $\mathrm{CuO} / \mathrm{ZnO} / \mathrm{Al}_{2} \mathrm{O}_{3}$ catalyst, the reactions occur on the catalyst surface and the generated heat is transferred to the syngas in the tube side. The outlet product from gas cooled reactor enters to the separation section to produce pure methanol. Table 1 shows the reactor design data, catalyst characteristics and feed specifications of the dual type configuration [22].

\subsection{Process modeling}

\subsubsection{Reaction kinetics}

Typically, the $\mathrm{CO}$ and $\mathrm{CO}_{2}$ hydrogenation and the watergas shift reactions occur on the surface of $\mathrm{CuO} / \mathrm{ZnO} / \mathrm{Al}_{2} \mathrm{O}_{3}$ catalyst. The kinetics of reactions are as [23]:

$$
\mathrm{CO}+2 \mathrm{H}_{2} \leftrightarrow \mathrm{CH}_{3} \mathrm{OH} \quad \Delta H_{298}=-90.5\left(\mathrm{~kJ} \mathrm{~mol}^{-1}\right)
$$

$\mathrm{CO}_{2}+3 \mathrm{H}_{2} \leftrightarrow \mathrm{CH}_{3} \mathrm{OH}+\mathrm{H}_{2} \mathrm{O} \quad \Delta H_{298}=-49.43\left(\mathrm{~kJ} \mathrm{~mol}^{-1}\right)$

$$
\mathrm{CO}_{2}+\mathrm{H}_{2} \leftrightarrow \mathrm{CO}+\mathrm{H}_{2} \mathrm{O} \quad \Delta H_{298}=+41.12\left(\mathrm{~kJ} \mathrm{~mol}^{-1}\right)
$$

Based on the presented data in the literature, the rate of $\mathrm{CO}$ and $\mathrm{CO}_{2}$ hydrogenation and the water-gas shift reactions are as follows [24]: 


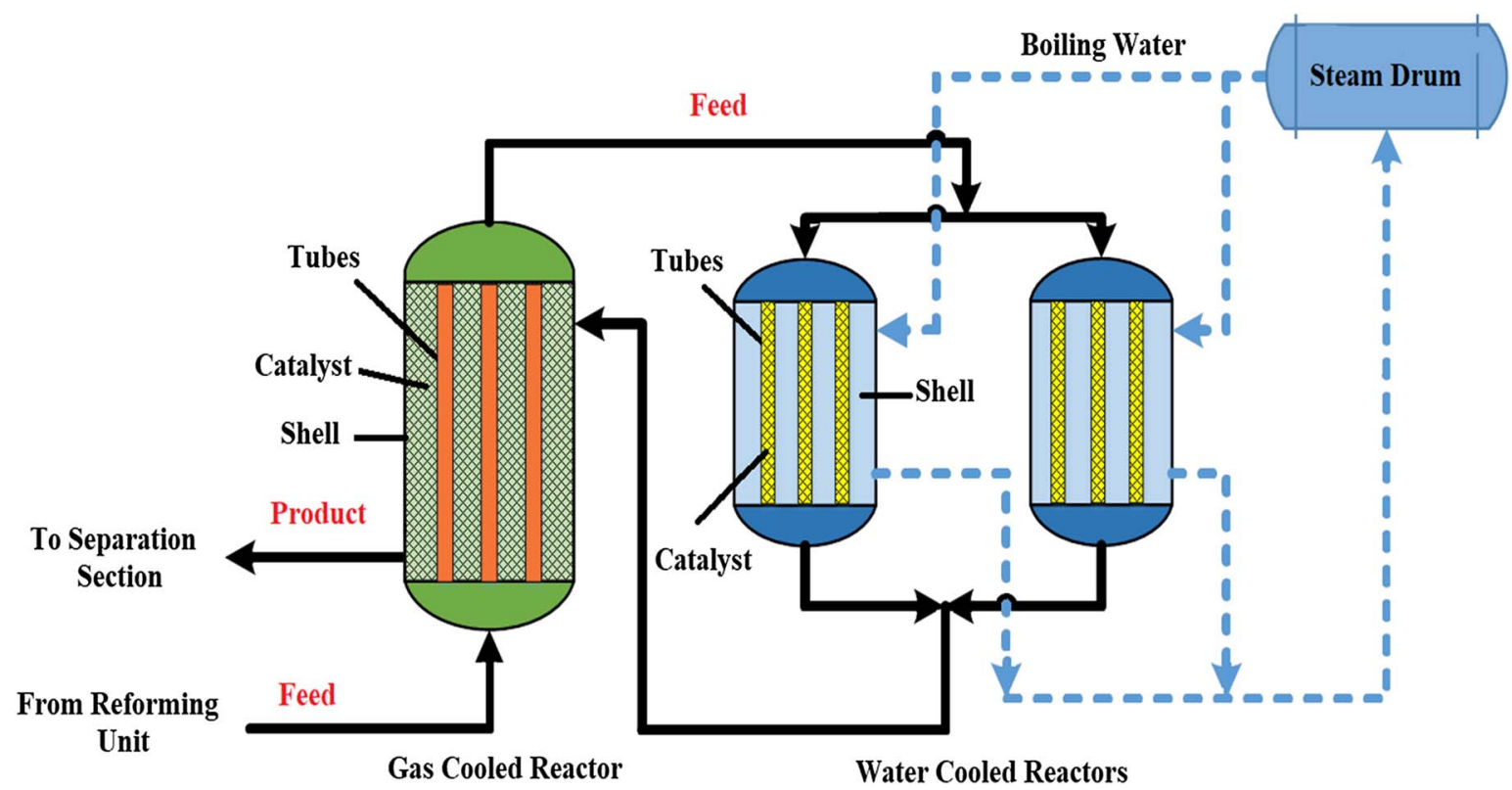

Fig. 1. Schematic diagram of dual-type configuration.

Table 1. Catalyst, reactor and feed specifications.

\begin{tabular}{|c|c|c|c|}
\hline & Parameter & $\begin{array}{l}\text { Water } \\
\text { cooled }\end{array}$ & $\begin{array}{l}\text { Gas } \\
\text { cooled }\end{array}$ \\
\hline \multirow[t]{2}{*}{ Catalyst } & Density $\left(\mathrm{kg} \mathrm{m}^{-3}\right)$ & 2390 & 2390 \\
\hline & Diameter $(\mathrm{cm})$ & 0.574 & 0.574 \\
\hline \multirow[t]{6}{*}{ Reactor } & Diameter $(\mathrm{m})$ & 4.5 & 5.5 \\
\hline & $\begin{array}{l}\text { Tube inner diameter } \\
(\mathrm{cm})\end{array}$ & 4.03 & 2.12 \\
\hline & $\begin{array}{l}\text { Tube outer diameter } \\
(\mathrm{cm})\end{array}$ & 4.45 & 2.54 \\
\hline & Length $(\mathrm{m})$ & 8.4 & 10.5 \\
\hline & Number of tubes & 5955 & 3026 \\
\hline & Bed void fraction & 0.39 & 0.39 \\
\hline \multirow[t]{10}{*}{ Feed } & $\mathrm{CO}(\%)$ & 8.61 & 8.61 \\
\hline & $\mathrm{CO}_{2}(\%)$ & 9.87 & 9.87 \\
\hline & $\mathrm{H}_{2}(\%)$ & 64.02 & 64.02 \\
\hline & $\mathrm{CH}_{4}(\%)$ & 8.35 & 8.35 \\
\hline & $\mathrm{N}_{2}(\%)$ & 8.45 & 8.45 \\
\hline & $\mathrm{CH}_{3} \mathrm{OH}(\%)$ & 0.43 & 0.43 \\
\hline & $\mathrm{H}_{2} \mathrm{O}$ & 0.09 & 0.09 \\
\hline & Feed flow rate $\left(\right.$ mole s $\left.^{-1}\right)$ & - & 931 \\
\hline & Inlet temperature $(\mathrm{K})$ & - & 401 \\
\hline & Inlet pressure (bar) & - & 75 \\
\hline
\end{tabular}

$$
r_{1}=\frac{k_{1} K_{\mathrm{CO}}\left[f_{\mathrm{co}} f_{\mathrm{H}_{2}}^{3 / 2}-f_{\mathrm{CH}_{3} \mathrm{OH}}\left(f_{\mathrm{H}_{2}}^{1 / 2} K_{\mathrm{p} 1}\right)\right]}{\left(1+K_{\mathrm{CO}} f_{\mathrm{CO}}+K_{\mathrm{CO}_{2}} f_{\mathrm{CO}_{2}}\right)\left[f_{\mathrm{H}_{2}}^{1 / 2}+\left(K_{\mathrm{H}_{2} \mathrm{O}} / K_{\mathrm{H}_{2}}^{1 / 2}\right) f_{\mathrm{H}_{2} \mathrm{O}}\right]}
$$

$$
\begin{aligned}
& r_{2}=\frac{k_{2} K_{\mathrm{CO}_{2}}\left[f_{\mathrm{CO}_{2}} f_{\mathrm{H}_{2}}^{3 / 2}-f_{\mathrm{CH}_{3} \mathrm{OH}} f_{\mathrm{H}_{2} \mathrm{O}}\left(f_{\mathrm{H}_{2}}^{3 / 2} K_{\mathrm{p} 2}\right)\right]}{\left(1+K_{\mathrm{CO}} f_{\mathrm{CO}}+K_{\mathrm{CO}_{2}} f_{\mathrm{CO}_{2}}\right)\left[f_{\mathrm{H}_{2}}^{1 / 2}+\left(K_{\mathrm{H}_{2} \mathrm{O}} / K_{\mathrm{H}_{2}}^{1 / 2}\right) f_{\mathrm{H}_{2} \mathrm{O}}\right]} \\
& r_{3}=\frac{k_{3} K_{\mathrm{CO}_{2}}\left[f_{\mathrm{CO}_{2}} f_{\mathrm{H}_{2}}-f_{\mathrm{H}_{2} \mathrm{O}} f_{\mathrm{CO}} K_{\mathrm{p} 3}\right]}{\left(1+K_{\mathrm{CO}} f_{\mathrm{CO}}+K_{\mathrm{CO}_{2}} f_{\mathrm{CO}_{2}}\right)\left[f_{\mathrm{H}_{2}}^{1 / 2}+\left(K_{\mathrm{H}_{2} \mathrm{O}} / K_{\mathrm{H}_{2}}^{1 / 2}\right) f_{\mathrm{H}_{2} \mathrm{O}}\right]} .
\end{aligned}
$$

Since the gas is at ideal condition, the fugacity of components is replaced by partial pressure. In this research, the reaction rate, adsorption and equilibrium constants are selected from literature [12]. In the methanol plant, the activity of catalyst decreases due to chemical and thermal sintering [10]. Catalyst deactivation decreases the rate of reactions and results in the lower syngas conversion. Thus, selection of an appropriate correlation to predict the catalyst activity plays an important role in the model accuracy and reliability. In this research, the proposed deactivation model by Hanken is selected to apply in the model [25].

$$
\frac{\mathrm{d} a}{\mathrm{~d} t}=-K_{d} \exp \left(\frac{-E_{d}}{R}\left(\frac{1}{T}-\frac{1}{T_{R}}\right)\right) a^{5} .
$$

\subsubsection{Modeling of methanol synthesis reactors}

In this research, the water cooled reactor is modeled based on the mass and energy balance equations at dynamic condition. The following assumptions are applied in the model:

- axial dispersion of mass and energy is negligible due to large Peclet [26], 
- the mass and heat transfer resistances in the gas phase are negligible [12],

- flow regime in the tube side is Plug due to large Reynolds Number,

- the temperature gradient in the catalyst is negligible due to small Biot [27].

The mass and energy balance equations on the water cooled reactor are as follows:

$$
\begin{gathered}
\varepsilon_{B} C_{t} \frac{\partial y_{i}}{\partial t}=-\frac{F_{t}}{A_{c}} \frac{\partial y_{i}}{\partial z}+\sum_{j=1}^{3} \eta_{j} r_{i, j} \rho_{B} a \\
\varepsilon_{B} C_{t} C_{p} \frac{\partial T}{\partial t}=-\frac{F_{t}}{A_{C}} C_{p} \frac{\partial T}{\partial z}+\rho_{B} a \sum_{j=1}^{3} \eta_{j} r_{j}\left(-\Delta H_{j}\right) \\
+\frac{\pi D_{i}}{A_{C}} U\left(T_{c}-T\right) .
\end{gathered}
$$

The pressure drop along the bed is calculated by Tallmadge equation [28]:

$$
\frac{\Delta P}{l}=\left(\frac{150}{\operatorname{Re}} \frac{(1-\varepsilon)^{2}}{\varepsilon^{3}}+\frac{4.2}{\operatorname{Re}^{1 / 6}} \frac{(1-\varepsilon)^{1.166}}{\varepsilon^{3}}\right) \frac{u^{2} \rho}{D} .
$$

In the gas cooled reactor feed stream flows in the tube side, while the shell side is packed with the catalyst particles. The produced heat in the shell side is transferred to the tube side and temperature of fresh feed increases gradually. The mass and energy balance equations for the shell side of gas cooled reactor are as follows:

$$
\begin{gathered}
\varepsilon_{B} C_{t} \frac{\partial y_{i}}{\partial t}=-\frac{F_{t}}{A_{c}} \frac{\partial y_{i}}{\partial z}+\sum_{j=1}^{3} \eta_{j} r_{i, j} \rho_{B} a \\
\varepsilon_{B} C_{t} C_{p} \frac{\partial T_{s}}{\partial t}=-\frac{F_{s}}{A_{s}} C_{p} \frac{\partial T_{s}}{\partial z}+\rho_{B} a \sum_{j=1}^{3} \eta_{j} r_{j}\left(-\Delta H_{j}\right) \\
+\frac{\pi D_{p}}{A_{s}} U\left(T_{p}-T_{s}\right) .
\end{gathered}
$$

The pressure drop along the shell side of gas cooled reactor is calculated by Tallmadge equation. In addition, the energy balance equation for the cooling gas in tube side is as follows:

$$
C_{t} C_{p} \frac{\partial T_{p}}{\partial t}=-\frac{F_{p}}{A_{t}} C_{p} \frac{\partial T_{p}}{\partial z}+\frac{\pi D_{p}}{A_{t}} U\left(T_{s}-T_{p}\right) .
$$

The catalyst effectiveness factor, $\eta_{j}$, is calculated based on the dusty gas model [29]. It is defined as the ratio of the actual reaction rate in the catalyst to the calculated rate when the concentration and temperature gradients are negligible in the catalyst. The effectiveness factor could be explained as:

$$
\eta=\frac{\left.D_{e} A_{C} \frac{\mathrm{d} C_{i}}{\mathrm{~d} r}\right|_{r=R}}{r_{i}\left(\frac{1}{6} \pi d_{p}^{3}\right)}
$$

In this research, the effectiveness factor is calculated based on the Thiele modulus method. In this regard, the intrinsic rate of each reaction is explained by a first-order power law model in each element of reactor and the concentration distribution in the catalyst is obtained analytically. Equation (15) illustrates the analytical expression of effectiveness factor:

$$
\eta=\frac{1}{\varphi^{2}}\left(\varphi \operatorname{coth}(3 \varphi)-\frac{1}{3}\right)
$$

\subsubsection{Supplementary equations}

In this section, the considered equations to calculate the physical, and thermal properties and transfer coefficients are presented. Table 2 shows the used correlation to calculate physical properties and transfer coefficients.

\subsection{Numerical solution}

The developed equations in the modeling subsection are solved numerically based on a two steps solution. In the first step, the equations are solved by Euler method at steady state condition and the obtained solution is considered as the initial condition of dynamic model. In the second stage, the dynamic model is reduced to a set of ordinary differential equations by the method of line and the obtained ODE set is solved numerically. The considered procedure to solve obtained set of equations is as:

- guess a temperature for inlet stream to the water cooled reactor,

- solve the water cooled model and calculate the outlet composition and temperature,

- solve the gas cooled model and calculate feed temperature based on the outlet product from water cooled reactor and guessed temperature,

- if the absolute difference between calculated feed temperature and plant data is negligible go to the next time step,

- if the absolute difference is considerable, correct the guessed temperature.

\subsection{Process optimization}

The main object of this research is dynamic optimization of the syngas conversion section in the methanol plant to increase methanol production and $\mathrm{CO}_{2}$ conversion. Thus, the considered objective functions are higher methanol production and carbon dioxide conversion. Typically, there are two manipulated variables in the methanol synthesis section including feed temperature in the gas cooled and cooling temperature in the water cooled reactors to control the process performance at the desired conditions. Since CO and $\mathrm{CO}_{2}$ hydrogenation reactions are exothermic and reversible, heat management is a practical solution to overcome the equilibrium limitations and decreasing the effects of catalyst deactivation on the methanol production. Thus, as well as feed temperature in the gas cooled and cooling temperature in the water cooled reactors, the temperature 
Table 2. Correlation to calculate physical properties and transfer coefficients [29-31].

\begin{tabular}{|c|c|c|}
\hline Parameter & Equation & \\
\hline Specific heat capacity & $\frac{C_{p, i}}{R}=A_{i}+B_{i} T+C_{i} T^{2}+D_{i} T^{3}$ & (16) \\
\hline Mixture specific heat capacity & $C_{p, m}=\sum y_{i} C_{p, i}$ & $(17)$ \\
\hline Component viscosity & $\mu_{i}=2.6693 \times 10^{-5} \sqrt{\frac{\mathrm{Mw} T}{\sigma^{2} \Omega_{\mu}}}$ & $(18)$ \\
\hline Mixture viscosity & $\mu_{m}=\frac{\sum y_{i} \mu_{i} \mathrm{Mw}_{i}^{0.5}}{\sum y_{i} \mathrm{Mw}_{i}^{0.5}}$ & $(19)$ \\
\hline Binary diffusion coefficient & $D_{i j}=0.0019 \sqrt{\frac{1}{\mathrm{Mw}_{i}}+\frac{1}{\mathrm{Mw}_{j}}} \frac{T^{1.5}}{P \sigma^{2} \Omega_{D_{\mathrm{AB},}{ }^{\mu}}}$ & $(20)$ \\
\hline Diffusion coefficient in mixture & $D_{i m}=\frac{1-y_{i}}{\sum \frac{y_{i}}{D_{i j}}}$ & $(21)$ \\
\hline Thermal conductivity & $\lambda_{i}=\frac{A_{i} T^{B_{i}}}{1+\frac{C_{i}}{T}+\frac{D_{i}}{T^{2}}}$ & $(22)$ \\
\hline Mixture thermal conductivity & $\lambda_{m}=\frac{\sum y_{i} \lambda_{i} \mathrm{Mw}_{0}^{0.5}}{\sum y_{i} \mathrm{Mw}_{i}^{.0 .5}}$ & $(23)$ \\
\hline Heat transfer coefficient & $h_{g}=0.6\left(\frac{\lambda_{m}}{D_{c}}\right) \operatorname{Re}^{\frac{1}{2}} \operatorname{Pr}^{\frac{1}{3}}$ & $(24)$ \\
\hline
\end{tabular}

of inlet stream to the catalytic section of gas cooled and water cooled reactors are considered as the manipulated variables. In this regard, two heat exchangers are placed on the streams to manipulate temperature. The considered strategy increases number of manipulated variables in the system and results in the better heat management. To formulate an optimization problem, the considered objectives are combined to develop a single objective by $e$-constraint method. In this regard, the methanol production capacity is selected as the objective function, while $\mathrm{CO}_{2}$ conversion is set as the constraint. The $\mathrm{CO}_{2}$ conversion in the conventional process is selected as the lower bound of $\mathrm{CO}_{2}$ conversion in the modified process. In addition, the upper bound of temperature is set to be $543 \mathrm{~K}$ to avoid catalyst deactivation by thermal sintering [32]. The formulated optimization problem is:

$$
\begin{gathered}
J=\int_{0}^{t_{f}} F_{\mathrm{MeOH}} \mathrm{d} t \\
T_{(x . t)}<543 \\
x_{\mathrm{CO}_{2}}>15.54 \% .
\end{gathered}
$$

The genetic algorithm as an efficient optimization method is selected to handle the formulated optimization problem. It is a global optimization technique based on the natural selection that mimics biological evolution. The algorithm repeatedly modifies a population using a technique inspired by natural evolution and uses random genetic operators such as mutation, selection and crossover [33]. In this research, the genetic algorithm parameters such as initial population, generation and stall generation limit are selected to be 200, 400 and 100, respectively. In addition, the mutation rate and cross over fraction are 0.01 and 0.8 , respectively. The selection, cross over and mutation
Table 3. Comparison between simulation results and plant data for fresh catalyst.

\begin{tabular}{lccc}
\hline $\begin{array}{l}\text { Component mole } \\
\text { fraction }\end{array}$ & \multicolumn{2}{c}{ Reactor outlet } & $\begin{array}{c}\text { Absolute } \\
\text { error }\end{array}$ \\
\cline { 2 - 3 } & Simulation & $\begin{array}{c}\text { Plant } \\
\text { data }\end{array}$ & \\
\hline $\mathrm{CH}_{3} \mathrm{OH}$ & 0.0969 & 0.0977 & 0.818 \\
$\mathrm{H}_{2}$ & 0.5548 & 0.5558 & 0.18 \\
$\mathrm{CH}_{4}$ & 0.0972 & 0.0963 & 0.93 \\
Temperature (K) & 480.9 & 487.9 & 1.43 \\
\hline
\end{tabular}

steps are implemented based on tournament, intermediate and uniform methods.

\section{Results and discussion}

In this section, the simulation results are presented at dynamic state, and the performance of considered cases are compared at the same feed condition. In the conventional process, the feed temperature in the gas cooled and coolant temperature in the water cooled reactors are the manipulated variables. In Dual Configuration (DC) as the base case, the manipulated variables are unchangeable during the process run time. In Optimized Dual Configuration (ODC) as the second case, the optimal dynamic conditions of the base case are determined based on the formulated optimization problem. In the Optimized Dual Configuration (OMDC) as the third case, the process is modified and the optimal dynamic trajectories of inlet temperatures in the gas cooled reactor, temperatures of the feed and cooling medium in the water cooled reactor are determined. To prove the validity of developed model, considered assumptions and selected 


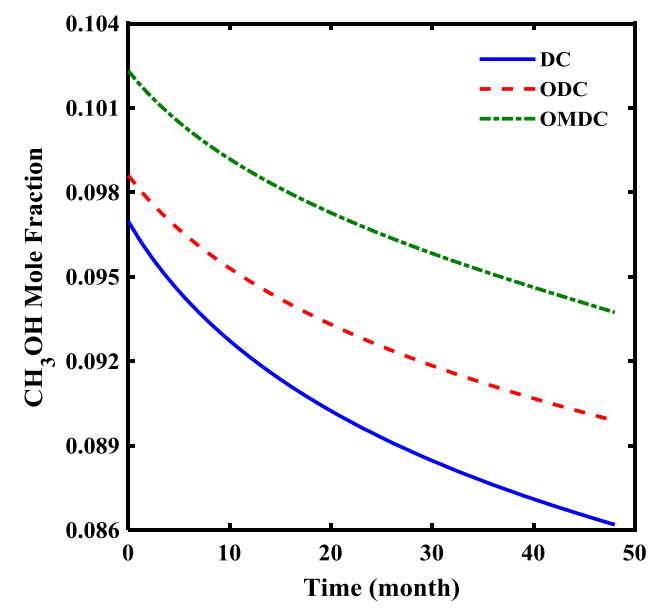

(a)

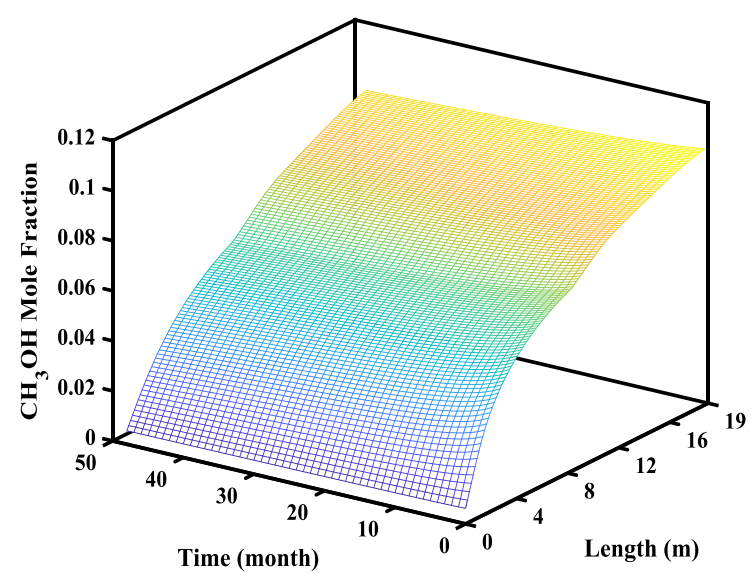

(b)

Fig. 2. a) Methanol mole fraction during process run time in DC, ODC and OMDC, and b) methanol mole fraction along the OMDC during the process run time.

kinetic equations and correlations, the results of simulation are compared with the available plant data in Table 3 [22]. It appears that there is a good agreement between plant data and simulation results at the same process condition. Thus, the developed model could be used in the optimization section to calculate the optimal conditions of process.

Figures $2 \mathrm{a}$ and $2 \mathrm{~b}$ show the methanol mole fraction in the outlet stream from gas cooled reactor during the process run time and methanol concentration in the third case. It appears that catalyst deactivation decreases production capacity in the methanol plant, and changing operating temperature is a practical solution to overcome the appeared decay. Based on the simulation results, the mean production capacity in DC, ODC and OMDC are 4564.48, 4693.92 and 4859.13 ton day $^{-1}$, respectively. Although applying the optimal trajectories on the base case increases methanol production by $2.83 \%$, supporting the process by two heat exchangers and applying the optimal trajectories on the system improves methanol production about $6.45 \%$. It appears that the methanol production rate in the base case decreases from 4853 to 4393 ton day ${ }^{-1}$ during the process run time. The production decay in DC, ODC and OMDC are about 460, 369 and 359 ton day $^{-1}$, respectively. It concludes that the main benefits of optimized process are the higher production capacity and lower production decay during the process run time.

Figures $3 \mathrm{a}-3 \mathrm{c}$ show the optimal trajectories of manipulated variables based on the formulated optimization problem in the second and third cases, respectively. Based on the simulation results, increasing temperature of cooling medium in the water cooled reactor and decreasing feed temperature in the gas cooled reactor could improve production capacity in the second case. Typically, catalyst deactivation reduces the rate of syngas conversion and results in the higher deviation from thermodynamic equilibrium. Increasing coolant temperature in the water cooled reactor promotes the rate of syngas conversion. On the other hand, applying the lower feed temperature in the gas cooled reactor shifts thermodynamic limitations and results in the higher equilibrium conversion. In the third case, increasing coolant temperature in the water cooled reactor increases the rate of hydrogenation reactions and could decrease the effect of catalyst deactivation on the rate. Since the gas cooled reactor is a counter-current heat exchanger, increasing temperature of inlet stream to the shell side increases operating temperature in the first half of reactor while decreasing temperature of inlet stream to the tube side reduces temperature in the second.

According to kinetic theory and Le Chatelier's principle, applying the high temperature in the first half of gas cooled reactor increases the rate of reactions, while low temperature in the second half shifts the thermodynamic equilibrium. It concludes that the developed temperature profiles along the gas and water cooled reactors in the third case result in the higher syngas conversion. It is confirmed that the calculated temperature trajectories are feasible and could be applied on the system by conventional heat exchangers. Figures $4 \mathrm{a}$ and $4 \mathrm{~b}$ show the methanol mole fraction along the gas and water cooled reactors at start of run and end of run conditions, respectively. Based on the kinetic model, $\mathrm{CO}$ and $\mathrm{CO}_{2}$ hydrogenation reactions compete to produce methanol. It appears that the methanol mole fraction increases along the gas and water cooled reactors and approaches to the equilibrium condition in all cases. Although the performance of first and second cases is similar when the catalyst is fresh, the second case presents the superior performance compared to the base when the catalyst presents lower activity.

The results show that the OMDC presents a superior performance over the DC and ODC due to better heat management in the system. Figures $5 \mathrm{a}-5 \mathrm{c}$ present the temperature profile along the water cooled and gas cooled reactors at different run times. Although increasing temperature enhances the rate in exothermic reversible reactions, it decreases equilibrium conversion in the system. In the dual type configuration, the feed stream is preheated in 


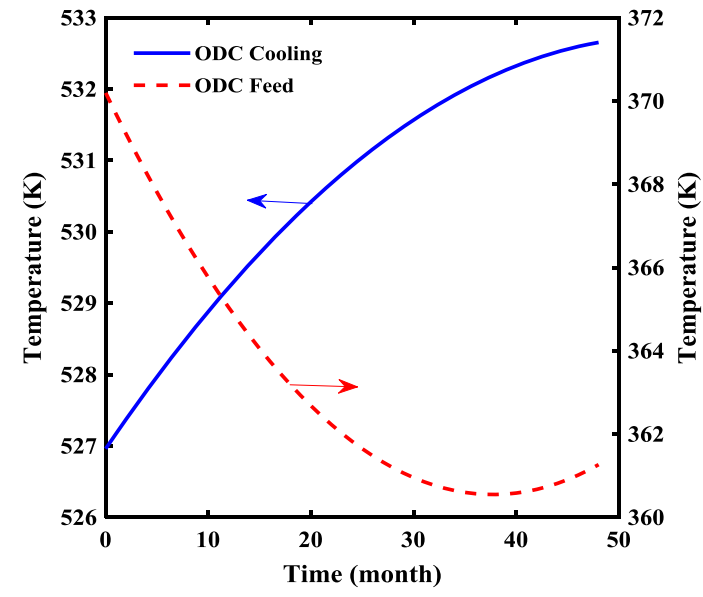

(a)

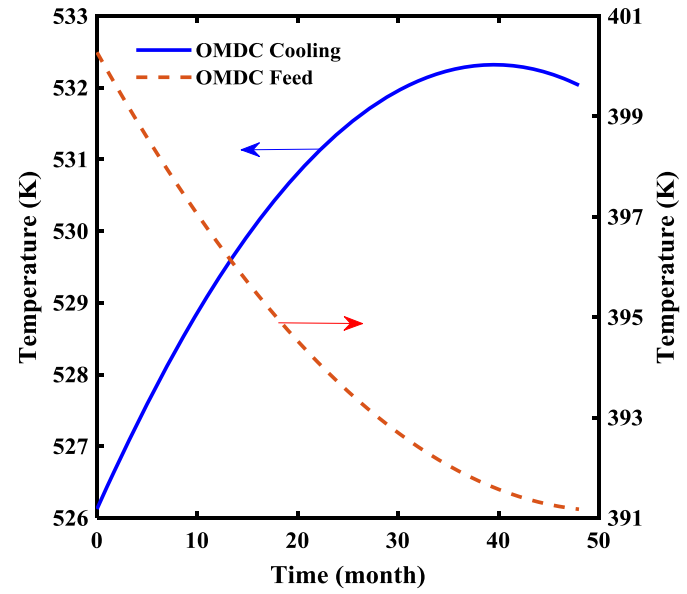

(b)

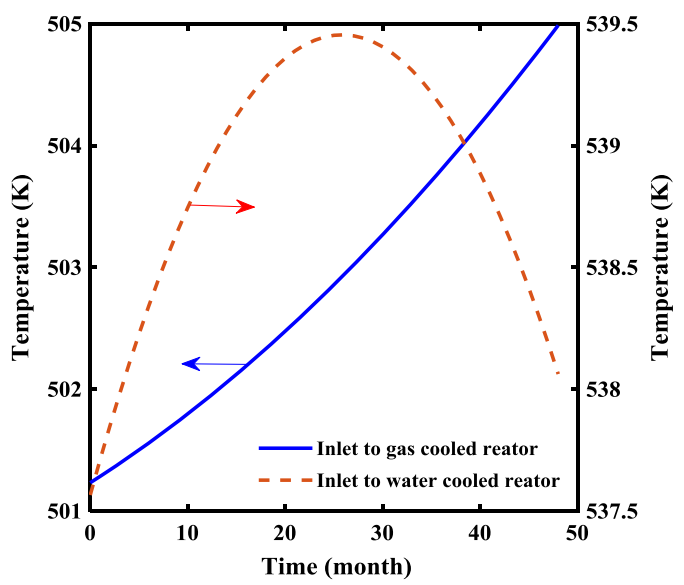

(c)

Fig. 3. a) The calculated optimal dynamic trajectory of manipulated variables in ODC, b) the calculated optimal dynamic trajectory of manipulated variables in OMDC and c) the calculated optimal dynamic trajectory of manipulated variables in OMDC.

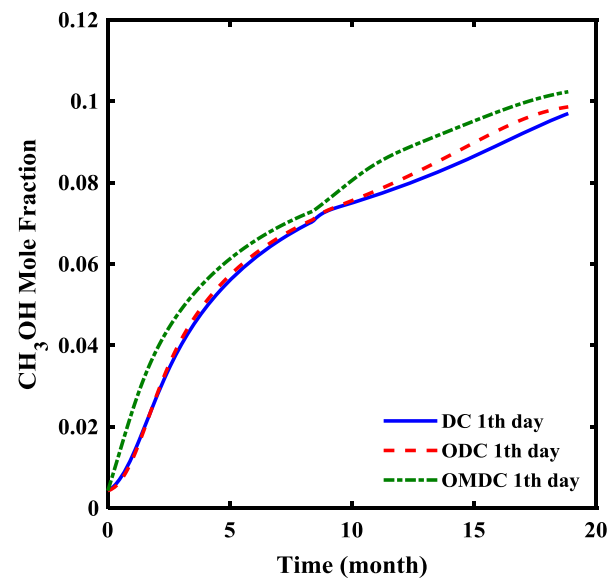

(a)

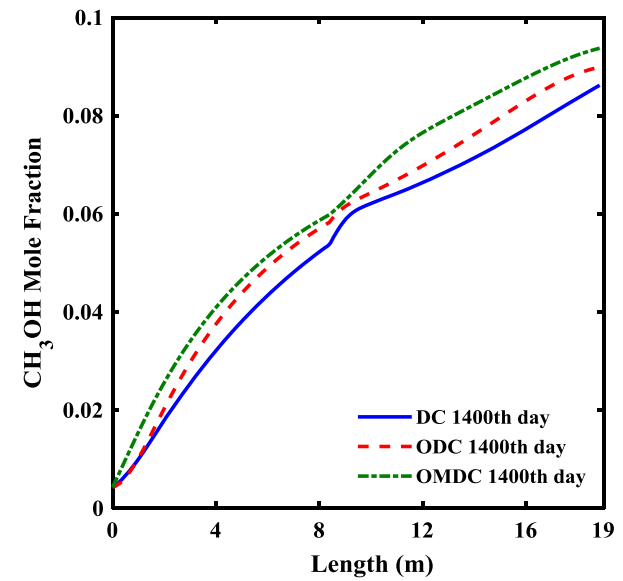

(b)

Fig. 4. a) The methanol production rate along the reactors at first day of operation and b) the methanol production rate along the reactors at 1400 th day of operation. 


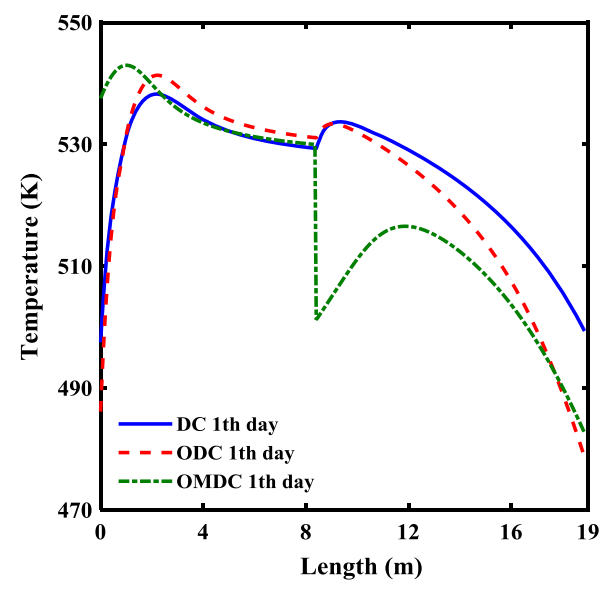

(a)

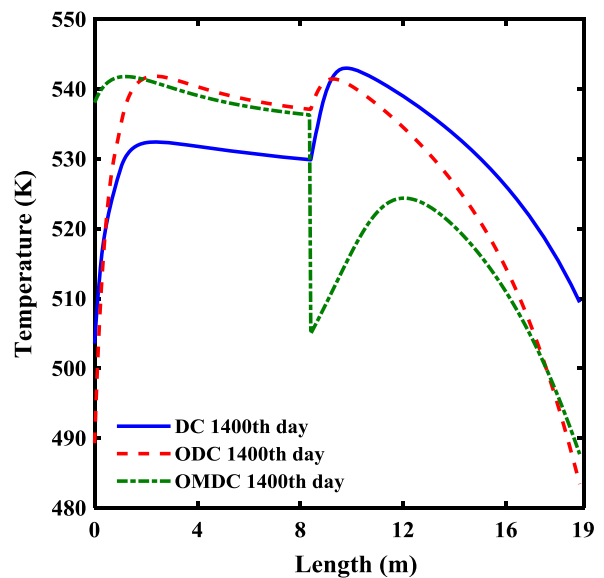

(b)

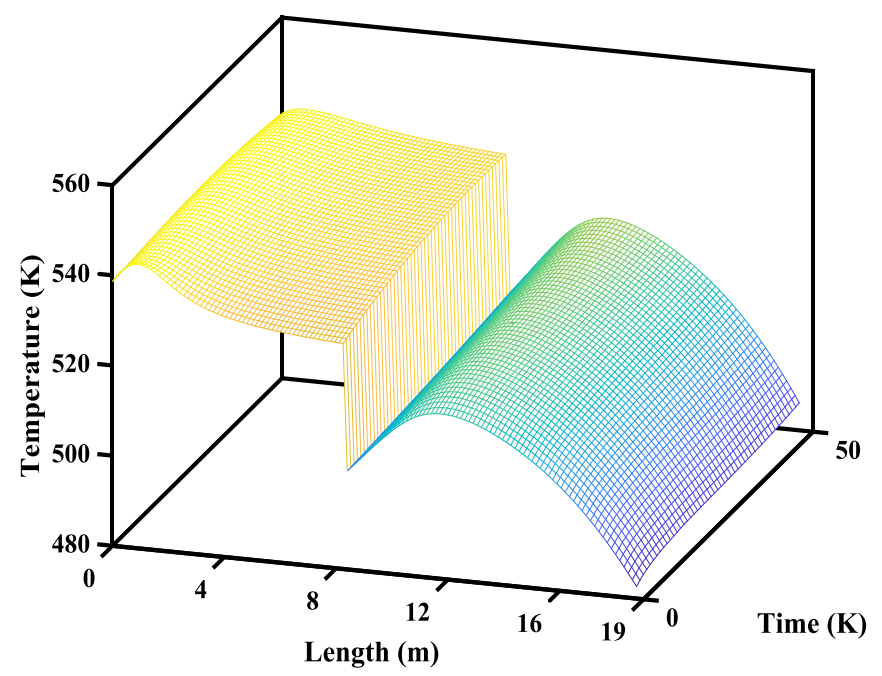

(c)

Fig. 5. a) The temperature profile along the reactors at first day of operation and b) the temperature profile along the reactors at 1400th day of operation, c) temperature profile along the OMDC during the process run time.

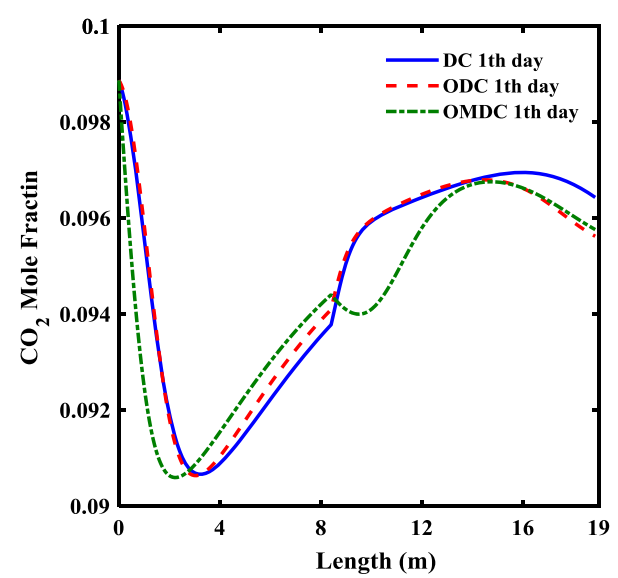

(a)

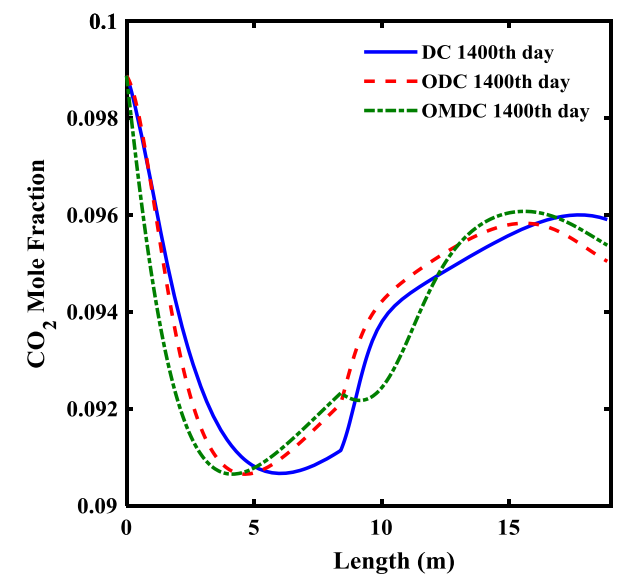

(b)

Fig. 6. a) $\mathrm{CO}_{2}$ concentration profile along the reactors at first day of operation and b) $\mathrm{CO}_{2}$ concentration profile along the reactors at 1400 th day of operation. 


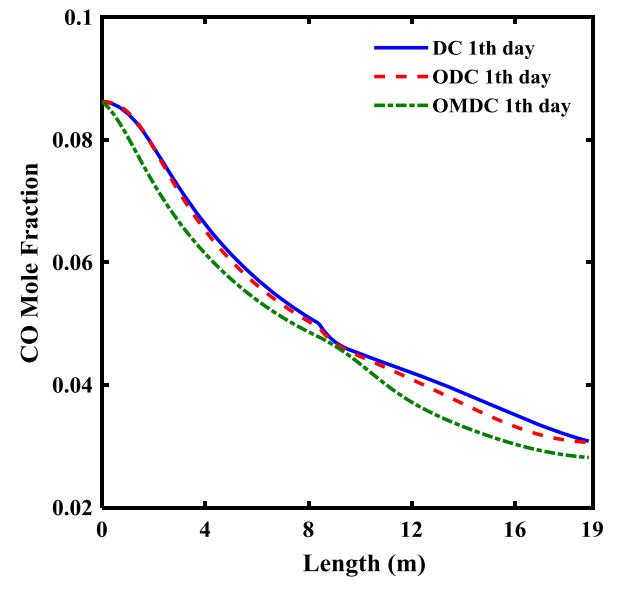

(a)

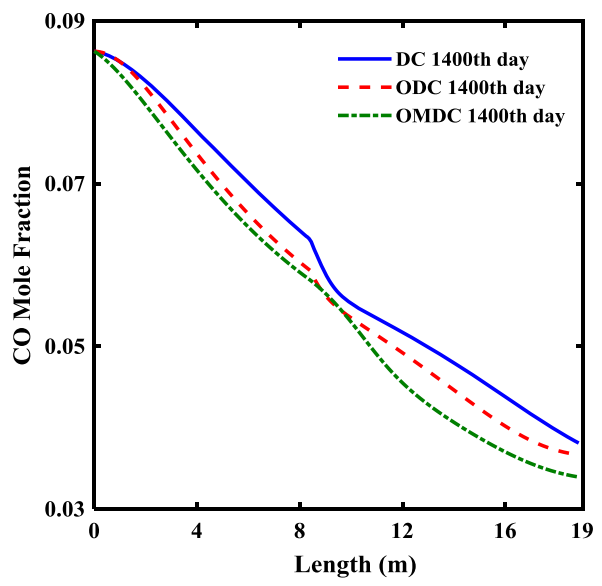

(b)

Fig. 7. a) CO concentration profile along the reactors at first day of operation and b) CO concentration profile along the reactors at 1400 th day of operation.

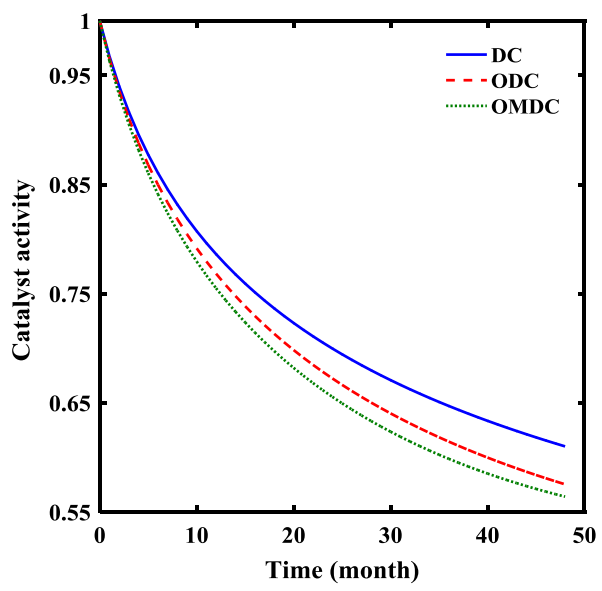

(a)

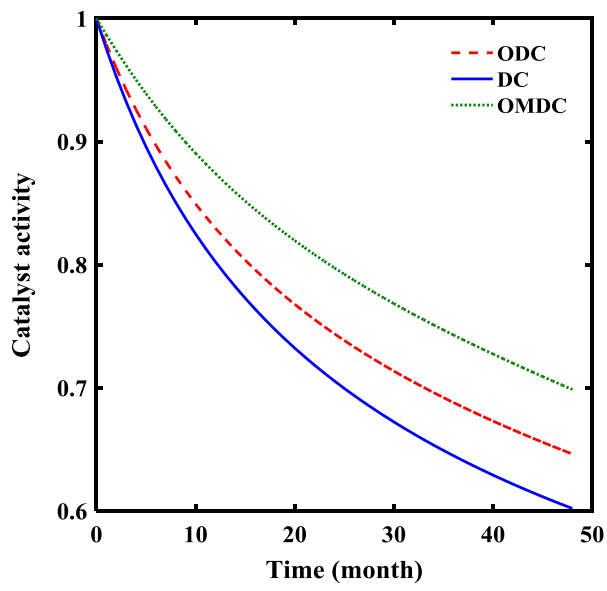

(b)

Fig. 8. a) Mean bed activity in the water cooled reactor and b) mean bed activity in the gas cooled reactor.

the gas cooled reactor and feeds to the tube side of water cooled reactor. Indeed, the water cooled reactor acts as the first catalytic section. Then, the outlet stream from water cooled feeds to the shell side of gas cooled reactor and syngas is converted to methanol over the catalyst surface. Thus, applying the high temperature on the water cooled reactor as the first catalytic part increases rate of reactions and system approaches to the equilibrium condition, while applying low temperature on the gas cooled reactor shifts the methanol synthesis reactions toward the right side and results in the higher methanol production. It concludes that the suitable heat management is the main advantage of OMDC over DC and ODC cases that results in the higher methanol production. Thus, supporting the base case by heat exchangers and applying the optimal trajectories on the system shifts the process toward the ideal condition and results in the higher methanol production. Since $\mathrm{CO}_{2}$ has a significant effect on the climate change and world warming, and it provides an available and inexpensive source to produce fuels and chemicals, $\mathrm{CO}_{2}$ conversion and recycling has received a significant attention in the world [34]. In this regard, improving methanol unit to increase rate of $\mathrm{CO}_{2}$ conversion is attractive.

Figures $6 \mathrm{a}$ and $6 \mathrm{~b}$ show the carbon dioxide concentration along the gas cooled and water cooled reactors in DC, ODC and OMDC at different run times. Based on the reaction network, $\mathrm{CO}_{2}$ hydrogenation and water gas shift reactions influence the $\mathrm{CO}_{2}$ concentration in the reactor. Although $\mathrm{CO}_{2}$ concentration decreases at the initial part of water cooled and the last part of gas cooled reactors, it increases along the other parts.

The lower carbon dioxide concentration in the outlet stream from gas cooled reactor in ODC and OMDC compared to the base case proves the higher $\mathrm{CO}_{2}$ conversion. Based on the simulation results, the mean $\mathrm{CO}_{2}$ conversion in the DC, ODC and OMDC is $15.54 \%, 16.74 \%$ and 
$17.04 \%$ at the same feed condition, respectively. Figures $7 \mathrm{a}$ and $7 \mathrm{~b}$ show the carbon monoxide concentration along the gas cooled and water cooled reactors in DC, ODC and OMDC at different run times. It appears that $\mathrm{CO}$ mole fraction decreases along the reactors gradually, and $\mathrm{CO}$ conversion to methanol in DC and ODC is similar when the catalyst is active. Based on the simulation results, decreasing catalyst activity reduces the rate of $\mathrm{CO}$ hydrogenation to methanol and applying the optimal conditions on the system could improve equilibrium conversion and rate of reactions.

It appears that third case presents a superior performance over the first and second cases to convert $\mathrm{CO}$ to methanol during the process run time. Based on the simulation results, the mean $\mathrm{CO}$ conversion in the first, second and third cases are $64.40 \%, 65.59 \%$ and $68.53 \%$ at the same feed conditions, respectively. Figures $8 \mathrm{a}$ and $8 \mathrm{~b}$ show the mean catalyst activity in the water cooled and gas cooled reactors, respectively. It appears that catalyst activity decreases during the process run time. Although the applied catalyst in water cooled reactor in OMDC presents lower activity because of higher operating temperature, the catalyst with more activity is appeared in the gas cooled reactor due to lower operating temperature. On the other word, the effect of low catalyst activity in the water cooled reactor on the methanol production rate is overcome by applying the high feed temperature, and the equilibrium conversion in the gas cooled reactor is improved by applying low feed temperature in the OMDC. In addition, the applied catalyst in gas cooled reactor in OMDC presents the higher activity compared to dual and optimized DCs.

\section{Conclusion}

In this research, the methanol synthesis section in the dual type configuration was modeled and optimized in the presence of catalyst deactivation. Based on the simulation results, deactivation of $\mathrm{CuO} / \mathrm{ZnO} / \mathrm{Al}_{2} \mathrm{O}_{3}$ catalyst by sintering and low equilibrium conversion of hydrogenation reactions limited the production capacity in the methanol plant. In this regard, the reactors were modeled based on the mass and energy balance equations at dynamic condition. Then, a dynamic optimization problem was formulated to calculate the optimal trajectories of manipulated variables in the base case. Although the feed temperature in the gas cooled and coolant temperature in the water cooled reactors were manipulated variables in the base case, applying two exchangers on the system increased the number of manipulated variables in the system. Based on the simulation results, the mean production capacity in the base case, ODC and OMDC was 4564.48, 4693.92 and 4859.13 ton day $^{-1}$, respectively. Although, applying the optimal operating condition on the conventional process increased methanol production by $2.83 \%$, modification of the base case by heat exchangers and applying the optimal condition on the system improved methanol production about $6.45 \%$. In addition, the mean carbon dioxide conversion in the DC, ODC and OMDC configurations was $15.54 \%, 16.74 \%$ and $17.04 \%$ at the same feed condition, respectively.

\section{References}

1 Mäyrä O., Leiviskä K. (2018) Modeling in methanol synthesis, Methanol, Elsevier, pp. 475-492.

2 Dalena F., Senatore A., Marino A., Gordano A., Basile M., Basile A. (2018) Methanol production and applications: An overview, Methanol, Elsevier, pp. 3-28.

3 Alarifi A., Alsobhi S., Elkamel A., Croiset E. (2015) Multiobjective optimization of methanol synthesis loop from synthesis gas via a multibed adiabatic reactor with additional interstage $\mathrm{CO}_{2}$ quenching, Energy Fuels 29, 2, 530537.

4 Tursunov O., Kustov L., Kustov A. (2017) A brief review of carbon dioxide hydrogenation to methanol over copper and iron based catalysts, Oil Gas Sci. Technol. - Rev. IFP Energies nouvelles $\mathbf{7 2}, 5,30$.

5 Farsi M., Jahanmiri A. (2011) Methanol production in an optimized dual-membrane fixed-bed reactor, Chem. Eng. Process.: Process Intensification 50, 11-12, 1177-1185.

6 Wagialla K., Elnashaie S. (1991) Fluidized-bed reactor for methanol synthesis. A theoretical investigation, Ind. Eng. Chem. Res. 30, 10, 2298-2308.

7 Struis R.P.W.J., Stucki S., Wiedorn M. (1996) A membrane reactor for methanol synthesis, J. Membr. Sci. 113, 1, 93-100.

8 Rahimpour M., Bayat M., Rahmani F. (2010) Enhancement of methanol production in a novel cascading fluidized-bed hydrogen permselective membrane methanol reactor, Chem. Eng. J. 157, 2-3, 520-529.

9 Šetinc M., Levec J. (2001) Dynamics of a mixed slurry reactor for the three-phase methanol synthesis, Chem. Eng. Sci. 56, 21-22, 6081-6087.

10 Kung H.H. (1992) Deactivation of methanol synthesis catalysts - A review, Catal. Today 11, 4, 443-453.

11 Liu X.-M., Lu G., Yan Z.-F., Beltramini J. (2003) Recent advances in catalysts for methanol synthesis via hydrogenation of $\mathrm{CO}$ and $\mathrm{CO}_{2}$, Ind. Eng. Chem. Res. 42, 25, 6518-6530.

12 Rezaie N., Jahanmiri A., Moghtaderi B., Rahimpour M. (2005) A comparison of homogeneous and heterogeneous dynamic models for industrial methanol reactors in the presence of catalyst deactivation, Chem. Eng. Process: Process Intensification 44, 8, 911-921.

13 Jahanmiri A., Eslamloueyan R. (2002) Optimal temperature profile in methanol synthesis reactor, Chem. Eng. Commun. 189, 6, 713-741.

14 Kordabadi H., Jahanmiri A. (2005) Optimization of methanol synthesis reactor using genetic algorithms, Chem. Eng. J. 108, 3, 249-255.

15 Fuad M.N.M., Hussain M.A., Zakaria A. (2012) Optimization strategy for long-term catalyst deactivation in a fixedbed reactor for methanol synthesis process, Comput. Chem. Eng. 44, 104-126.

16 Rahimpour M. (2007) A dual-catalyst bed concept for industrial methanol synthesis, Chem. Eng. Commun. 194, 12, 1638-1653.

17 Askari F., Rahimpour M.R., Jahanmiri A., Khosravanipour Mostafazadeh A. (2008) Dynamic simulation and optimization of a dual-type methanol reactor using genetic algorithms, Chem. Eng. Technol.: Ind. Chem. Plant Equip. Process Eng. Biotechnol. 31, 4, 513-524.

18 Farsi M., Jahanmiri A. (2014) Dynamic modeling and operability analysis of a dual-membrane fixed bed reactor to produce methanol considering catalyst deactivation, J. Ind. Eng. Chem. 20, 5, 2927-2933. 
19 Rahimpour M., Elekaei H. (2009) Enhancement of methanol production in a novel fluidized-bed hydrogen-permselective membrane reactor in the presence of catalyst deactivation, Int. J. Hydrogen Energy 34, 5, 2208-2223.

20 Rahimpour M., Bayat M., Rahmani F. (2010) Dynamic simulation of a cascade fluidized-bed membrane reactor in the presence of long-term catalyst deactivation for methanol synthesis, Chem. Eng. Sci. 65, 14, 4239-4249.

21 Dehghani Z., Bayat M., Rahimpour M. (2014) Sorptionenhanced methanol synthesis: Dynamic modeling and optimization, J. Taiwan Inst. Chem. Eng. 45, 4, 1490-1500.

22 Mirvakili A., Rahimpour M. (2015) Mal-distribution of temperature in an industrial dual-bed reactor for conversion of $\mathrm{CO}_{2}$ to methanol, Appl. Thermal Eng. 91, 1059-1070.

23 Son M., Park M.-J., Kwak G., Park H.-G., Jun K.-W. (2018) Maximum production of methanol in a pilot-scale process, Korean J. Chem. Eng. 35, 2, 355-363.

24 Graaf G., Stamhuis E., Beenackers A. (1988) Kinetics of low-pressure methanol synthesis, Chem. Eng. Sci. 43, 12, 3185-3195.

25 Hanken L. (1995) Optimization of methanol reactor, Master's Thesis, The Norwegian University of Science and Technology, Norway.
26 Alam I., West D.H., Balakotaiah V. (2016) Transport effects on pattern formation and maximum temperature in homogeneous-heterogeneous combustion, Chem. Eng. J. 288, 99-115.

27 Holman J. (2002) Heat transfer, 9th Edn., McGraw Hill, New York, USA.

28 Tallmadge J. (1970) Packed bed pressure drop - An extension to higher Reynolds numbers, AIChE J. 16, 6, 1092-1093.

29 Fogler H.S. (2010) Essentials of chemical reaction engineering, Pearson Education, London, UK.

30 Green D.W., Perry R.H. (1999) Perry's Chemical Engineers' handbook, McGraw-Hill Professional, New York, USA.

31 Stewart W.E., Lightfoot E.N., Bird R.B. (1962) Transport phenomena, John Wiley \& Sons, New York, USA.

32 Løvik I., Hillestad M., Hertzberg T. (1998) Long term dynamic optimization of a catalytic reactor system, Comput. Chem. Eng. 22, S707-S710.

33 Holland J., Goldberg D. (1989) Genetic algorithms in search, optimization and machine learning, Addison-Wesley, MA, USA.

34 Leonzio G. (2017) Optimization through response surface methodology of a reactor producing methanol by the hydrogenation of carbon dioxide, Processes 5, 4, 62 . 